EVIDENCE BASED PUBLIC HEALTH POLICY AND PRACTICE

\title{
Substantial use of primary health care by prisoners: epidemiological description and possible explanations
}

\author{
J M Feron, D Paulus, R Tonglet, V Lorant, D Pestiaux
}

J Epidemiol Community Health 2005;59:651-655. doi: 10.1136/jech.2004.022269

See end of article for authors' affiliations

a...

Correspondence to: Dr J M Feron, Centre Universitaire de Médecine Générale, Université Catholique de Louvain, Avenue Mounier 5360, 1200 Brussels, Belgium Jean-Marc.Feron@cumg. ucl.ac.be

Accepted for publication 22 March 2005

\begin{abstract}
Objectives: To describe the use of primary care services by a prisoner population so as to understand the great number of demands and therefore to plan services oriented to the specific needs of these patients. Design: Retrospective cohort study of a sample of prisoners' medical records.

Setting: All Belgian prisons $(n=33)$.

Patients: 513 patients over a total of 182 patient years, 3328 gneral practitioner (GP) contacts, 3655 reasons for encounter.

Main results: Prisoners consulted the GP 17 times a year on average (95\% Cl 15 to 19.4). It is 3.8 times more than a demographically equivalent population in the community. The most common reasons for encounter were administrative procedures $(22 \%)$ followed by psychological (13.1\%), respiratory (12.9\%), digestive (12.5\%), musculoskeletal (12\%), and skin problems (7.7\%). Psychological reasons for consultations $(n=481)$ involved mainly $(71 \%)$ feeling anxious, sleep disturbance, and prescription of psychoactive drugs. Many other visits concerned common problems that in other circumstances would not require any physician intervention.

Conclusion: The most probable explanations for the substantial use of primary care in prison are the health status (many similarities noted between health problems at the admission and reasons for consultations during the prison term: mental health problems and health problems related to drug misuse), lack of access to informal health services (many contacts for common problems), prison rules (many consultations for administrative procedures), and mental health problems related to the difficulties of life in prison.
\end{abstract}

$\mathrm{T}$ he use of primary health care in the prison population is considerable compared with the general community. In the UK, prisoners consult their general practitioner (GP) three times more than a demographically equivalent population in the community. ${ }^{1}$ In France ${ }^{2}$ and Belgium, an average of $10 \%$ of the prisoner population are seen on each working day in general practice. ${ }^{3}$ According to European Council, ${ }^{4}$ prisoners should have full and unlimited access to a doctor or nurse as necessary. However, demand for health care often seems to outstrip the capacity of services. ${ }^{5}$ Access to services is only limited by GPs' availability and medical consultations have therefore become very brief and deal only with the presenting complaint. ${ }^{6}$

In Belgium GPs play a central part in the delivery of primary care to prisoners. They see most prisoners' health problems. GPs ensure a gate keeping role for access to specialists or for hospital admission. All consulting physicians in Belgian prisons are also GPs working in the community. Consultations are free of charge. There is no waiting list and every prisoner can consult daily. Nurses mainly ensure the organisation of the consultation and follow up (drug treatment, medical care). They also ensure a variable part of lay care.

The electronic medical record used in all Belgian prisons contains two essential components for describing the use of primary health care and for developing explanatory hypotheses:

- GP contacts during imprisonment, recorded in chronological order permitted the analysis of reasons for encounter and their incidence. Whenever a date and a GP's name were present, we considered that there had been a contact. In most cases, one or several reasons for encounter and/or a treatment is specified. Contacts are at the intersection of supply and demand and thus reflect use of services.
- The medical examination on arrival at the prison contains information on all health problems whether resolved or ongoing at the time of committal. The prevalence of these problems helps to formulate explanatory hypotheses (that is, influence of health status on use of services).

Scarce research has attempted to give an epidemiological analysis of the use of primary care by prisoners, nor has any tried to explain the substantial demand for primary care in this population. It is widely accepted that the prevalence of mental health problems, ${ }^{78}$ drug misuse, ${ }^{910}$ and infectious diseases $^{11}{ }^{12}$ is high but its impact on use of primary health care is unknown.

The aim of this study is to describe the use of primary care services by the prisoner population and to attempt to explain the high demands so as to prioritise and plan services oriented to the specific needs of this population. ${ }^{13}{ }^{14}$

\section{METHODS}

The study design was a retrospective cohort study of discharged prisoners. Sampling was done using the prison files. These are completely distinct from medical files. We identified all prisoners released from a Belgian prison from 1 September to 30 November $2002(n=3510)$ from the list of prison files. A systematic random selection was then carried out to obtain the sample size. Medical files were then retrieved.

The sample size was calculated to obtain a $5 \%$ precision (95\% confidence intervals) for the prevalence of health problems on committal. Five hundreds and thirteen records were analysed, 475 for men and 38 for women. Table 1 describes the sample characteristics.

Analysis of GP contacts concerned the previous year of imprisonment. No less than a year to avoid seasonal effects, no more than a year because electronic records were 


\begin{tabular}{|c|c|c|c|c|c|c|}
\hline $\begin{array}{l}\text { Number of } \\
\text { records }=513\end{array}$ & Mean & Min & Max & Median & P25 & P75 \\
\hline Age (years) & 34.10 & 18 & 73 & 33 & 26 & 40 \\
\hline $\begin{array}{l}\text { Length of stay in } \\
\text { prison (days) }\end{array}$ & 232 & 1 & 5467 & 84 & 30 & 205 \\
\hline
\end{tabular}

introduced in Belgium in 1999. Earlier data might have been of lower quality and with an overrepresentation of long sentences. Only 73 prisoners from the sample (14\%) were imprisoned for more than a year. A total of 182.2 patient years were analysed.

Health problems on committal (whether this was in the past year or not) and reasons for encounter in GP contacts were classified according to the International Classification for Primary Care. ${ }^{15}$ This classification is perfectly adapted to primary care setting where complaints do not always lead to a specific diagnosis.

We assessed the quality of textual notes in medical files by marking them from 0 to 2 . A " 0 " score was given when only a date was recorded for the encounter. A " 1 " score was given when notes were incomprehensible. A "2" score was given when notes were clear.

Textual data were coded by one researcher, independent of the prison health service, and not by physicians themselves, to improve reliability. ${ }^{16}$ Coding was done using standardised criteria of ICPC. When only a treatment was specified in the contact, code 50 (procedure: medication) was used. In other cases the reason(s) for encounter was (were) coded using written notes. Code 50-that is, "medication" entails an actual contact with a doctor to start or prolong a drug treatment. It does not just consist in a form filling exercise. When, for example, a sleep disturbance was noted (followed by a psychoactive treatment or not), only code P06 sleep disturbance was attributed.

When difficulties occurred in coding, data were cross coded independently by another researcher to assess coding quality.

Exel software was used to analyse data.

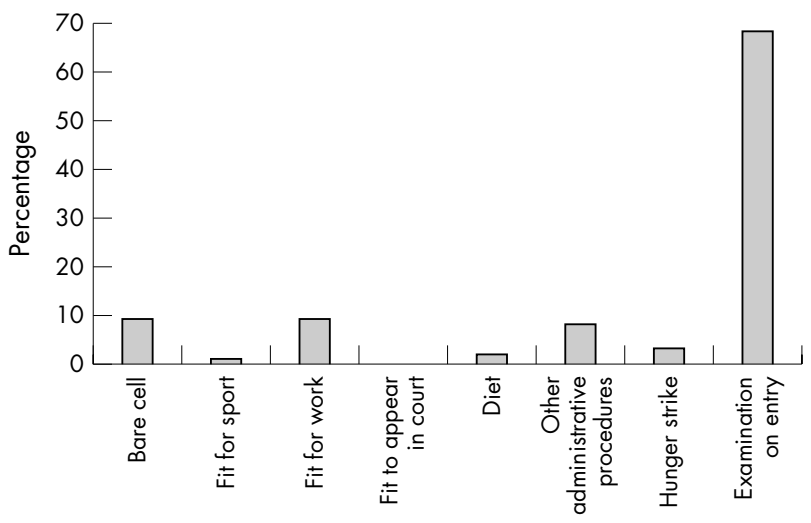

Figure 2 Administrative procedures: reasons for encounter (total number 793).

The research protocol was approved by an ethics committee (Université Catholique de Louvain, Brussels).

\section{RESULTS}

Excluding the examination on entry, prisoners consulted with their GP an average 17 times a year (95\% CI 15.0 to 19.4). Compared with a sex and age equivalent population in the community, ${ }^{17}$ the incidence ratio was 3.8 (95\% CI 3.3 to 4.2 ).

Regarding quality of textual notes, $97 \%$ of files received a "2" score and so were of satisfactory quality for analysis.

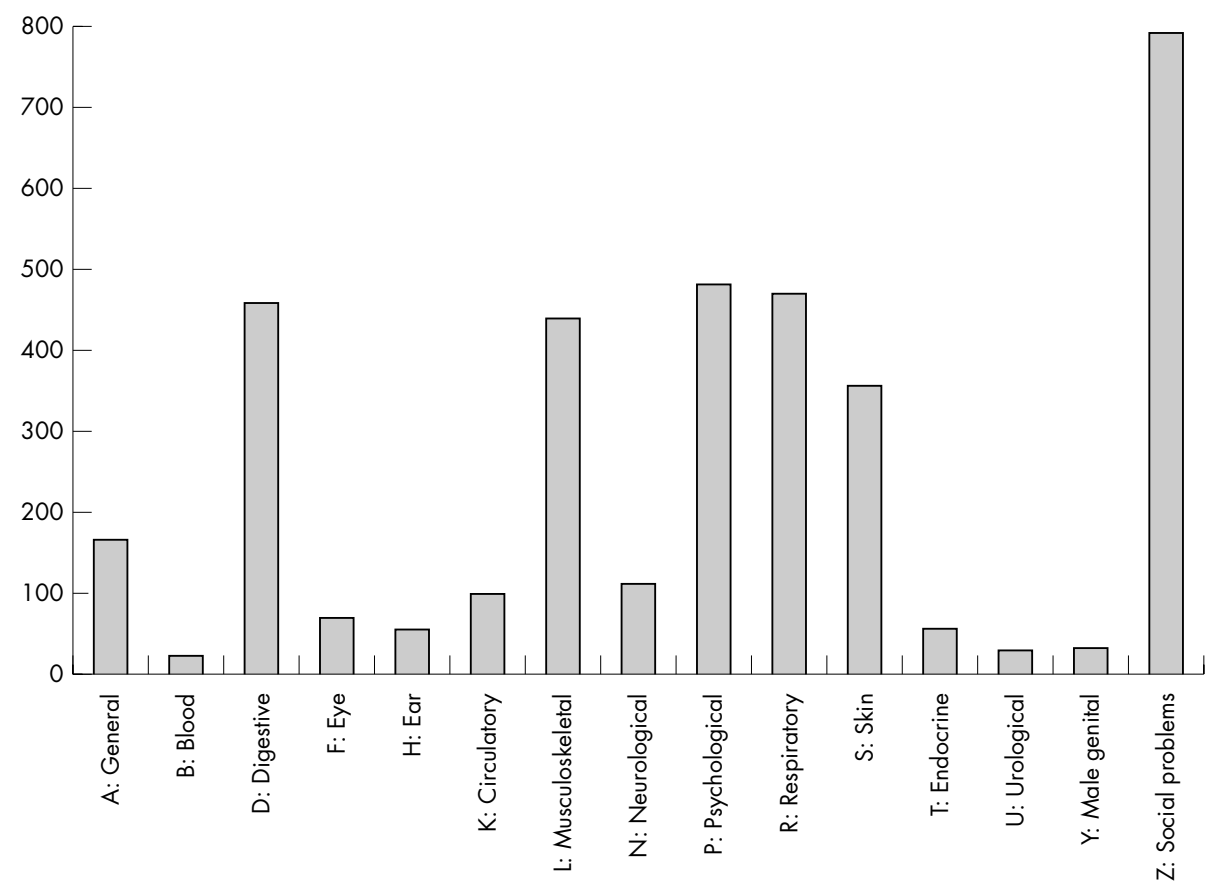

Figure 1 Reasons for encounter by ICPC coding (total number 3655); 182 patient years; 513 medical records. 


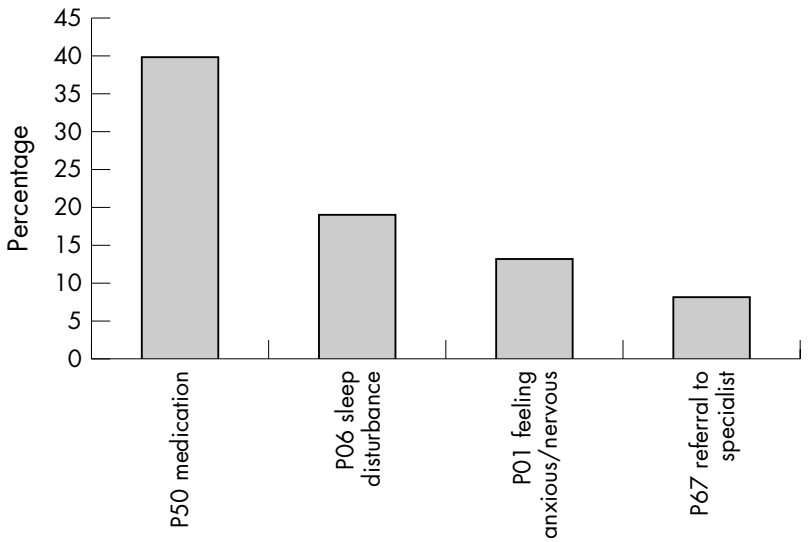

Figure 3 Coding psychological: top four of reasons for encounter $(n=481)$.

An average of 1.2 reasons for encounter was recorded for each contact. Figure 1 shows incidences of reasons for encounter in the 513 records analysed.

The most common reasons for encounter were administrative procedures (coding Z: $22 \%$ ), mental health problems (P: $13.1 \%)$, respiratory problems (R: $12.9 \%)$, gastrointestinal problems (D: 12.5\%), musculoskeletal problems (L: 12\%), and skin problems (S: 7.7\%). The low incidence of cardiovascular diseases (coding $\mathrm{K}$ ) is attributable to the average age of the prisoners in the sample (34 years).

Coding Z included mostly administrative procedures. Of 794 reasons for encounter, only one was truly a social issue. Figure 2 details the different administrative procedures.

Examination on entry was the most common administrative procedure. There were more examinations on entry (536) than files (513) because these examinations are carried out at every committal and at every transfer. The procedure referred to as bare cell is an examination carried out in to find out if a contraindication to placement in a punishment cell is present. Contacts with GPs classified as "other administrative procedure" refer to various issues such as "authorisation to wear slippers", "snores; solo cell", "daily shower", "refuses to be transferred to hospital".

Figures 3, 4, 5, 6, and 7 show the top four of reasons for encounter for each main ICPC coding (psychological, respiratory, digestive, musculoskeletal, and skin). For encounters at the prisoner's request, most medical complaints were of mental health issues $(n=481)$. Drug prescriptions (procedure 50) are among the top four reasons for encounter in each of these main ICPC codings.

Table 2 summarises health problems on committal. Problems that were totally resolved (for example, appendicectomy) or that accounted for less than $0.5 \%$ of problems were disregarded, their impact on demand for services considered minimal. Of 513 files analysed, 439 (86\%) contained a written record of the examination on entry. Prisoners imprisoned before the introduction of the electronic medical record in Belgian prisons had missing data.

The health status of prisoners is noticeably linked to behaviour in relation to addictions: drug misuse (most prevalent problem), medication misuse, alcoholism, hepatitis, asthma, allergic rhinitis, haemorrhoids, HIV.

\section{DISCUSSION}

The prisoner population consults with a GP 3.8 times more often than the rest of the population (result standardised according to age and sex, and excluding examination on entry-that is, $14.7 \%$ of reasons for encounter). This figure is consistent with findings by Marshall (incidence ratio 3, also

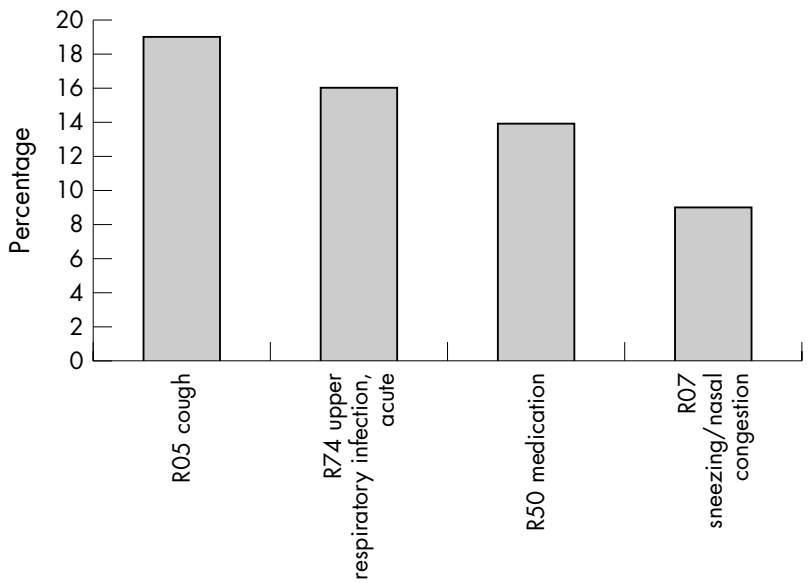

Figure 4 Coding respiratory: top four of reasons for encounter $(n=470)$.

standardised for age and sex) showing that the substantial use of primary care services in prison is common in Europe. There is however great individual variability in the use of health services by prisoners.

Disregarding the many administrative procedures carried out, most of the primary care services are used to deal with psychological, respiratory, gastrointestinal, musculoskeletal, and skin problems. Many contacts are motivated solely by the request for medication. An important part of the reasons for consultation are common problems that would mostly be sorted out in the community by the patient, their family, or through direct access to a pharmacy. The absence of access to informal health services is one factor for the high demands in prison.

Health status on committal plays a very important part in the use of medical services. The most common reasons for encounter (mental health, gastrointestinal, respiratory, dental) are linked to the most common problems recorded on entry (that is, addictions and associated diseases).

Together with the substantial pre-existing drug misuse problems, the difficult experience of imprisonment is clearly an issue. Psychoactive drugs are used both to alleviate the prisoner's suffering and to maintain the peace within the institution. ${ }^{18}$ Imprisonment itself fuels demand for medical services: prescription of psychoactive drugs, sleeping disturbance, anxiety, and administrative procedures.

These main explanations suggested by the data do not exclude other hypothesises: free access to consultations, secondary gains in seeing a GP, brief relief from boredom, hope for sedative drugs that could be misused or sold to other

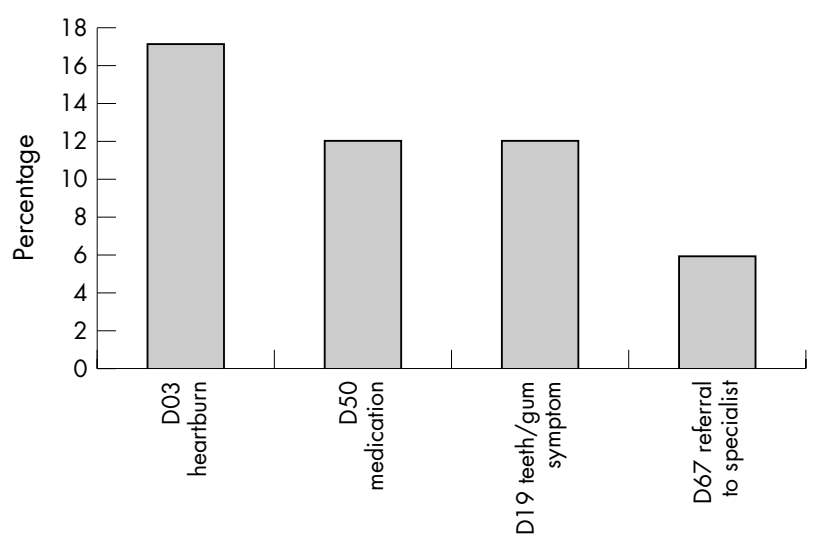

Figure 5 Coding digestive: top four of reasons for encounter $(n=458)$. 


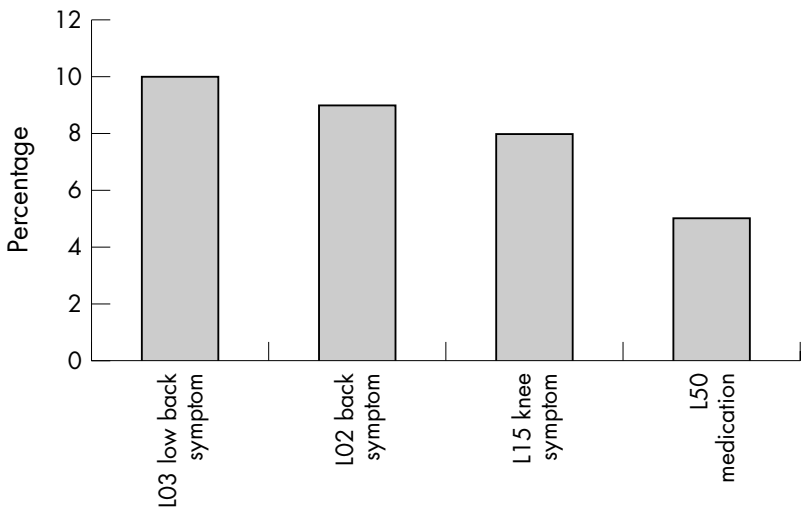

Figure 6 Coding musculoskeletal: top four of reasons for encounter $(n=439)$.

inmates, or lack of access to health care outside the prison for this socioeconomic deprived population.

Few data are available about primary care epidemiology in this specific population. This is, however, essential to analyse health demand and specific needs in this particular context. The weakness of a retrospective cohort study based on medical records is the inconstant quality of textual notes recorded. But $97 \%$ were of satisfactory quality for analysis. Furthermore, electronic files ensure that data are correctly dated, legible, and organised in a standardised fashion. Because examinations on entry are not standardised, these data are weaker. In particular, the prevalence of mental health problems at the time of committal (code P) might be underestimated in relation to the reality, through patient shyness or ignorance, or through doctor's being rushed.

On the other hand, one strength of this study is its retrospective design increasing the truthfulness of data. Health care in prison settings suffers usually from suspicion about its quality, accessibility, and transparency. This retrospective data collection did not permit the doctors to have improved their note taking to give a better image of the health care (Hawthorne effect).

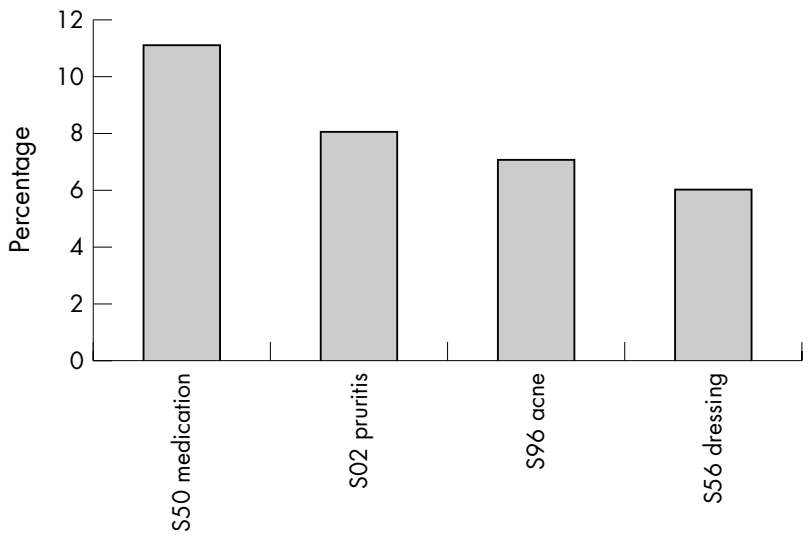

Figure 7 Coding skin: top four of reasons for encounter $(n=356)$.

The most probable explanations suggested by the data for the substantial use of primary care in the prison setting are: health status on entry (high prevalence of pre-existing mental health problems), lack of access to informal health services (many contacts for common problems), stringent rules (many contacts for administrative procedures), mental health issues related to the difficulties of life in prison (psychoactive drug prescriptions, nervousness).

Such descriptive studies are often the starting point for other studies concerning the main health problems of a specific population. Identifying the main health problems is however a necessary first step. More research should be carried out to estimate both quantitatively and qualitatively the specific health needs of prisoners to better organise services to cater for these needs. As an illustration, our results show that mental health issues are the most common reason for encounter after the administrative procedures. The results might yet underestimate the importance of mental health problems because assessing potential somatisations (for example, for complaints of headache or abdominal pain) is often difficult. Prevalence of mental health issues in prisons is an acute problem in the $\mathrm{UK}^{19}$ and probably in other

\begin{tabular}{|lllll}
\hline $\begin{array}{l}\text { Table 2 } \\
\text { ( } \mathrm{n}=\text { 439) }\end{array}$ & Health problems (current or past) self reported at the time of imprisonment \\
\hline ICPC code & Title & Number & \% & 95\% Cl \\
\hline P19 & Drug misuse & 97 & 22.1 & 18.2 to 26.0 \\
P15 & Chronic alcohol misuse & 21 & 4.8 & 2.8 to 6.8 \\
D72 & Viral hepatitis & 19 & 4.3 & 2.4 to 6.2 \\
R96 & Asthma & 17 & 3.9 & 2.1 to 5.7 \\
D86 & Peptic ulcer & 13 & 3.0 & 1.4 to 4.5 \\
A70 & Tuberculosis & 10 & 2.3 & 0.9 to 3.7 \\
N88 & Epilepsy & 10 & 2.3 & 0.9 to 3.7 \\
P76 & Depressive disorder & 10 & 2.3 & 0.9 to 3.7 \\
P18 & Medication misuse & 8 & 1.8 & 0.6 to 3.1 \\
R97 & Allergic rhinitis & 8 & 1.8 & 0.6 to 3.1 \\
K86 & Hypertension, uncomplicated & 6 & 1.4 & 0.3 to 2.5 \\
T90 & Diabetes, non-insulin dependent & 6 & 1.4 & 0.3 to 2.5 \\
D03 & Heartburn & 5 & 1.1 & 0.1 to 2.1 \\
K96 & Haemorrhoids & 5 & 1.1 & 0.1 to 2.1 \\
N01 & Headache & 5 & 1.1 & 0.1 to 2.1 \\
T92 & Gout & 5 & 1.1 & 0.1 to 2.1 \\
A92 & Allergy/allergic reaction & 4 & 0.9 & 0.0 to 2.0 \\
D02 & Abdominal pain, epigastric & 4 & 0.9 & 0.0 to 2.0 \\
B90 & HIV infection, AlDS & 3 & 0.7 & 0.0 to 2.0 \\
K75 & Acute myocardial infarction & 3 & 0.7 & 0.0 to 2.0 \\
K90 & Stroke/cerebrovascular accident & 3 & 0.7 & 0.0 to 2.0 \\
L86 & Back syndrome with radiating pain & 3 & 0.7 & 0.0 to 2.0 \\
P77 & Suicide/suicide attempt & 3 & 0.7 & 0.0 to 2.0 \\
S18 & Laceration/cut & 3 & 0.7 & 0.0 to 2.0 \\
T89 & Diabetes, insulin dependent & 3 & 0.7 & 0.0 to 2.0 \\
\hline & & & & \\
\hline & & & & \\
\hline
\end{tabular}




\section{Policy implication}

Like other countries in Europe, Belgium is transferring health care in prison settings from the Justice Ministry to Public Health Ministry. This research could help policy makers in their decisions and emphasises the importance of the independence of the health professionals within prison settings.

Western countries. Better education of nurses and GPs working in prisons on these issues could be a first step in catering for the specific needs of the prison population. Another step could be to reinforce the role of the prison nurse in dealing with common health problems.

This study contributes to the debate on the prison medicine, and especially on the tension between the obligation of access to medical care and the limits of health care services.

\section{ACKNOWLEDGEMENTS}

The authors thank Dr Francis Van Mol, director and Mr José Derlet, inspector of the Service de Santé Pénitentiaire, Ministère fédéral belge de la Justice.

\section{Authors' affiliations}

J M Feron, D Paulus, D Pestiaux, Centre Universitaire de Médecine Générale, Université Catholique de Louvain, Brussels, Belgium R Tonglet, V Lorant, Ecole de Santé Publique, Université Catholique de Louvain

Funding: none.

Conflicts of interest: none declared.

\section{REFERENCES}

1 Marshall T, Simpson S, Stevens A. Use of health services by prison prisoners: comparisons with the community. J Epidemiol Community Health $2001 ; 55: 364-5$.

2 Chauvin I. La santé en prison-les enjeux d'une véritable réforme de santé publique. Paris: ESF éditeur, 2000.

3 Ministère fédéral belge de la Justice. Données Service de Santé Pénitentiaire. Brussels: Ministère fédéral belge de la Justice, 2001.

4 European Council. Recommandation $R(98) 7$ du comité des ministres aux états membres relative aux aspects éthiques et organisationnels des soins de santé en milieu pénitentiaire. Comité des Ministres du Conseil de l'Europe, 8 Apr 1998.

5 Marshall T, Simpson S, Stevens A. Toolkit for health care needs assessment in prisons. J Public Health Med 2001;23:198-204.

6 Milly B. Soigner en prison. Paris: Presse Universitaire de France, 2001:148.

7 Fazel S, Danesh J. Serious mental disorder in 23000 prisoners: a systematic review of 62 surveys. Lancet 2002;359:545-50.

8 WHO regional office for Europe. Mental health promotion in prisons-report on a WHO meeting. The Hague: WHO, 1998.

9 Birchard K. Europe-wide survey finds widespread drug abuse in prisons. Lancet 2001;358:821.

10 Observatoire européen des drogues et des toxicomanies. Etat du phénomène de la drogue dans I'Union Européenne et en Norvège Rapport annuel 2003. OEDT. http://www.emcdda.eu.int.

11 Rotily M, Weilandt C, Bird S, et al. Surveillance of HIV infection and related risk behaviour in European prisons. European Journal of Public Health $2001 ; 11: 243-50$

12 Allwright S, Barry J, Reynolds SR, et al. Long J. Prevalence of antibodies to hepatitis B, hepatitis $C$, and HIV and risk factors in entrants to Irish prisons: a national cross sectional survey BMJ 2001;323:1209-13.

13 Pencheon D, Guest C, Melzer D, et al. Oxford handbook of public health practice. Oxford: Oxford University Press, 2001:40.

14 Shanks J, Kheraj S, Fish S. Better ways of assessing health needs in primary care. BMJ 1995;310:480-1.

15 Wonca International Classification Committee. International classification of primary care 2. 2nd ed. Oxford: Oxford Medical Publications, 1998.

16 Thiru K. Systematic review of scope and quality of electronic patient record data in primary care. BMJ 2003;326:1070.

17 Institut Scientifique de la Santé Publique Enquête de santé par interview Belgique 2001. http://www.iph.fgov.be/epidemio/epifr/index4.htm.

18 Jaeger M, Monceau M. La consommation des médicaments psychotropes en prison. Paris: Edition érès, 1996.

19 Stephenson P. Mentally ill offenders are being wrongly held in prisons. BMJ 2004;328:1095. 